\title{
Acaricide resistance in the spinose ear tick, Otobius megnini (Acari: Argasidae) infesting racehorses in Sri Lanka
}

\author{
GCP Diyes ${ }^{1,2}$, KMUJ Bandara ${ }^{1}$, RS Rajakaruna ${ }^{* 1}$ and SHPP Karunaratne ${ }^{1}$ \\ ${ }^{1}$ Department of Zoology, Faculty of Science, University of Peradeniya, Peradeniya. \\ ${ }^{2}$ Department of Biology, University of Saskatchewan, 112 Science Place, Saskatoon, SK S7N 5E2, Canada.
}

\begin{abstract}
The spinose ear tick Otobius megnini is a causative agent of otoacariasis in horses and jockeys in the Nuwara Eliya racecourses. The present study aimed at investigating the status of acaricide resistance and underlying mechanisms in this tick species under laboratory conditions. Live ticks collected from the ear canal of horses were used to establish a laboratory colony. Larval bioassays were carried out with an organophosphate (malathion), pyrethroids (flumethrin and permethrin), and an organochlorine (DDT) using Larval Packet Tests (LPT). The $\mathrm{LC}_{50}(24 \mathrm{~h})$ values for malathion, flumethrin, permethrin and DDT were recorded as $0.11 \%, 0.0003 \%, 0.008 \%$ and $0.124 \%$, respectively, and the respective values for $\mathrm{LC}_{90}$ were $0.722 \%$, $0.004 \%, 0.300 \%$ and $3.049 \%$. Biochemical assays revealed that the mean specific activity levels of esterase, glutathione S-transferases (GSTs), and monooxygenase amounts were $0.064 \pm 0.008 \mu \mathrm{mol} \mathrm{min}{ }^{-1} \mathrm{mg}^{-1}, 0.104 \pm 0.050 \mu \mathrm{mol} \mathrm{min}{ }^{-1} \mathrm{mg}^{-1}$, and $0.068 \pm 0.020$ equivalent units of cytochrome P450, respectively. The percentage remaining activity of the propoxur-inhibited Acetylcholinesterase (AChE) was $33.88 \pm$ $13.60 \%$. Our data indicated that the O. megnini population of Nuwara Eliya, Sri Lanka was most susceptible to flumethrin and showed resistance to DDT. Development of resistance to malathion through increased activity of esterase and insensitive AChEs was evident. Since the activities of monooxygenases and GSTs were not enhanced, permethrin and DDT resistance may have developed through target site insensitivity.
\end{abstract}

Keywords: Biochemical assays, DDT, ectoparasiticidal, flumethrin, malathion, permethrin.

\section{INTRODUCTION}

The spinose ear tick Otobius megnini (Acari: Argasidae) is a nidicolous soft tick whose immature stages (larvae and nymphs) parasitize domestic animals and occasionally humans causing otoacariasis. Otobius megnini has four developmental stages in its life cycle: egg, larva, nymph and adult (male/female) and completes its life cycle on a single host with larvae and nymphs parasitizing for several days to months (Nava et al., 2009; Diyes \& Rajakaruna, 2017). The unfed larvae are highly active, and it is the only life stage that participates in a hostseeking activity. Following attachment, larvae feed for 8-13 days before moulting to nymphs and these nymphs continue feeding for another 17-37 days. After that, fully engorged nymphs detach and moult to non-feeding adults on the ground. After successful mating, females lay eggs in a refuge. The life cycle of $O$. megnini stretches over 51 to 901 days (Diyes \& Rajakaruna, 2017). The life cycle duration strongly depends on the prevailing temperature and relative humidity. The presence of the tick inside the ear canal causes severe pain and irritation and can lead to toxic conditions, eardrum perforation, muscle spasms, and otitis (Madigan et al., 1995; Estrada-Peña \& Jongejan, 1999). Additionally, disease-causing agents such as Coxiella burnetii (Desjardins et al., 2018),

\footnotetext{
*Corresponding author (rupikar@pdn.ac.lk; (iD https://orcid.org/0000-0001-7939-947X)
} 
Borrelia burgdorferi (Fivaz et al., 1991) and Babesia (Diyes et al., 2018) have been detected in blood meal analysis of $O$. megnini.

In Sri Lanka, this tick species appears to have a limited distribution. To date, there are no records on $O$. megnini infestations in any domesticated animals except the horses and jockeys in the Nuwara Eliya racecourses. However, the dynamic nature of the life cycle with high population stability has enabled $O$. megnini to become an invasive tick species in the Nuwara Eliya racecourse. Controlling $O$. megnini using acaricides is not very common due to its presence in the ear canal of the horse. Current control practices used to manage O. megnini infestations include regular cleaning of the ear canals of the horses and frequent renewal of the sawdust inside the stables. However, effective complete control of O. megnini infestations is hard. Consequently, alternative control strategies, including vaccines and, synthetic and botanical acaricides are essential.

The application of synthetic acaricides such as carbamates, organophosphates, synthetic pyrethroids, formamidines, macrocyclic lactones and pyrazoles have played a pivotal role in controlling ticks worldwide (Lovis et al., 2011). However, the long-term use of these compounds has resulted in the development of acaricide resistance, thereby reducing the effectiveness (Graf et al., 2004). Therefore, constant monitoring of the level of susceptibility of pests to these chemicals is required to control the spread of any acquired resistance (Graf et al., 2004). However, to the best of our knowledge, there were no previously published reports on the susceptibility of O. megnini. Therefore, it is important to collect baseline data on the level of acaricide susceptibility of $O$. megnini.

In both insects and acarines, elevated enzymatic activity and target site insensitivity are the two major metabolic resistance mechanisms to insecticides (Karunaratne et al., 2018). The high enzymatic activity involves variations in insecticide metabolizing enzymes, i.e., esterases, glutathione-S-transferases (GSTs) and monooxygenases, which metabolize the acaricide before reaching the target site. However, target site insensitivity is the inability of mutated target sites to recognize the acaricide. Recently, Bandara and Karunaratne (2017) reported that DDT and malathion resistance in the cattle tick Rhipicephalus microplus from Sri Lanka was caused by both elevated esterase activity and insensitive target sites. Here, we determined the status of acaricide susceptibility of $O$. megnini larvae against four commonly used acaricides: malathion, flumethrin, permethrin, and DDT. The activity of acaricide metabolizing enzymes, and the insensitivity of the organophosphate and carbamate target site to acetylcholinesterase were also investigated to understand the potential mechanism of resistance.

\section{METHODOLOGY}

\section{Tick collection and rearing}

Live specimens of $O$. megnini were collected from 14 stabled thoroughbred horses in a racecourse in Nuwara Eliya (GPS: 6.9628 N 80.7692 E). Immediately after collecting the ticks, they were transferred to a laboratory facility where they were weighed and separated according to life stage. Fully engorged nymphs weighing over 60 mg were used to establish the laboratory tick colony. Nymphs were not fed after the collection because female ticks do not require an additional blood-meal to produce eggs (Diyes \& Rajakaruna, 2017). Tick rearing chambers were prepared according to Sonenshine (1993) and were maintained at $28 \pm 2^{\circ} \mathrm{C}$ under $96 \%$ relative humidity (RH) until nymphs molted into adults. New horse-bloodfed nymphs were introduced biweekly to the tick-rearing chambers to maintain a high genetic diversity in the colony.

In total, 100 engorged females, weighing from 60 to $120 \mathrm{mg}$, were used in this study. Each female was transferred into a separate slot of a 30-well plastic grid plate. Multiple plates were used to house all the females. After that, males were introduced to each female. Plates containing mating pairs were placed in a glass chamber kept in darkness and maintained at $28 \pm 2^{\circ} \mathrm{C}$ under $96 \%$ $\mathrm{RH}$ until oviposition. The eggs obtained from multiple females were mixed, subdivided into groups of 150 and then transferred into Eppendorf ${ }^{\circledR}$ tubes with perforated caps. Eggs, and later larvae, were maintained under the same conditions as those of females. Tubes were monitored daily for any fungal or mite infestations and were changed whenever contamination was observed. The tick colonies were maintained between September 2014 and March 2015. Larvae at the age of 14 to 21 days were used for all the bioassays.

\section{Acaricide bioassays}

A total of 8,408 larvae of $O$. megnini were subjected to acaricide bioassays. Acaricide bioassays were conducted using four technical grade acaricides, i.e., organochlorine (DDT), organophosphate (malathion) and two pyrethroids (permethrin and flumethrin) (Sigma Chemicals, UK) using the experimental protocol described by Larval Packet Test (LPT) (FAO, 2004). As there were no 
recommended dosages by FAO for soft ticks, the dosage recommended for hard ticks was used (Bandara \& Karunaratne, 2017). Acaricide solutions with different concentrations were prepared using olive oil:acetone ( $1: 2$; analytical grade) as the solvent. All concentrations used ranged from $10^{-6}$ to $10 \%$. These concentrations (v/v for malathion and w/v for DDT, flumethrin and permethrin) were determined using published dose-response data for ticks (Bandara \& Karunaratne, 2017; Miller et al., 1999) and by conducting preliminary studies. An aliquot of $0.7 \mathrm{~mL}$ from each dilution was evenly distributed on a Whatman No.1 filter paper $(7.5 \mathrm{~cm} \times 9.0 \mathrm{~cm})($ Miller et al., 1999) and the control received the solvent alone. Acaricide impregnated papers were wrapped individually in aluminium foil and stored at $4^{\circ} \mathrm{C}$ until the larvae reached 14-21 days old (FAO, 2004). They were used within a month after preparation, and each paper was used in a maximum of two trials/replicates (WHO, 2016) as follows. An acaricide impregnated paper was folded along the middle line with the impregnated surface inside and two bulldog clips were fixed on two opening sides, making a packet (FAO, 2004). Tick larvae (150 larvae) were inserted into the packet with the aid of a fine brush through the remaining open side and a third bulldog clip was used to seal the opening end. The packets were kept in separate humidity chambers with a temperature of $27-28^{\circ} \mathrm{C}$, and $85-95 \% \mathrm{RH}$. Mortality was recorded after $24 \mathrm{~h}$ after exposure to the treatment. Larvae that did not show a response to a needle touch were considered dead. A hand lens was used to confirm the response, whenever necessary. According to FAO (2004), if the mortalities of the controls were less than $5 \%$ of the mortalities of the treated, sample mortalities can be directly used for analyses without correction. However, if control mortalities were between $5-10 \%$, the mortalities of the treated sample must be adjusted using Abbott's formula (FAO, 2004). Since there were no mortalities observed in the controls, the mortalities of the treated samples were processed normally. All the acaricide bioassays were performed in triplicate.

\section{Statistical analysis}

Mortality values were plotted against acaracide concentrations to obtain log concentration-probit regression lines using Sigma Plot software (version 10.0). For each tested acaricide, lethal concentrations that kill $50 \%\left(\mathrm{LC}_{50}\right)$ and $90 \%\left(\mathrm{LC}_{90}\right)$ of the packet population, confidence intervals (CI) of $95 \%$ and the slope of the regression line (through regression analysis) were determined. A Chi-square test was used to evaluate the goodness of fit of the linear regression to log concentration-probit transformed data. Resistance discriminating dosages were not available for $O$. megnini. Therefore, we adopted a method similar to Bandara and Karunaratne (2017) to evaluate the current resistance/ susceptibility status of $O$. megnini larvae. Here, the discriminating dosages available for Rhipicephalus microplus (Acari, Ixodidae) (FAO, 2004) were used to assess the susceptibility/resistance status of the O. megnini population: susceptible (98-100\% mortality), possible resistant (90-97.9\% mortality) and resistant ( $<90 \%$ of mortality) (WHO, 2016). Discriminating dosages given for anopheline mosquitoes (WHO, 2016) were also used to evaluate the susceptibility/resistance status due to the absence of discriminating dosages for $O$. megnini or other ticks.

\section{Biochemical assays}

All the biochemical assays were carried out according to the procedures recommended by WHO (1998a) with slight modifications. Randomly selected O. megnini larvae were subjected to total protein, esterase, glutathione S-transferase (GST), monooxygenase and acetylcholinesterase assays in two replicates. Larvae were homogenized in groups of 25 individuals in $150 \mu \mathrm{L}$ ice-cold distilled water. An aliquot of $50 \mu \mathrm{L}$ was taken for the two replicates of AChE assay and the rest was centrifuged at 13,000 rpm for $2 \mathrm{~min}$. The supernatant was used for esterase, GST, monooxygenase and protein assays (WHO, 1998a). This whole experiment was repeated 21 times. The average values from 21 homogenates (total number of larvae $=25 \times 21$ ) were used for the analysis. The results of the following biochemical assays are expressed as mean $\pm \mathrm{SD}$.

\section{Acetylcholinesterase assay}

Two $25 \mu \mathrm{L}$ aliquots of crude homogenate were added to two consecutive microtiter plate wells. The membranebound $\mathrm{AChE}$ in the mosquito homogenate was solubilized by adding $145 \mu \mathrm{L}$ of $1 \%$ (v/v) Triton X-100 in $0.1 \mathrm{M}$ phosphate buffer ( $\mathrm{pH} 7.8$ ). Ten microliters of the substrate solution dithobis-2 nitrobenzoic acid (DTNB) in phosphate buffer ( $\mathrm{pH}$ 7.0) was added to each aliquot. To one replicate, $25 \mu \mathrm{L}$ of acetylthiocholine iodide (ASChI) and propoxur solution (10 mL of $0.01 \mathrm{M} \mathrm{ASChI}$ $20 \mu \mathrm{L}$ of $0.1 \mathrm{M}$ propoxur in acetone) were added. To the other replicate, $25 \mu \mathrm{L}$ of $0.01 \mathrm{M} \mathrm{ASChI}$ alone was added. The plate was read at $405 \mathrm{~nm}$ for $5 \mathrm{~min}$. Results were expressed as the percentage remaining activity in the inhibited fraction and was compared with the control (uninhibited) activity (WHO, 1998b). 


\section{Glutathione-S-transferase assay}

To prepare the working solution, $0.5 \mathrm{~mL}$ of $63 \mathrm{mM}$ I-chloro-2,4-dinitro benzene (CDNB) in methanol and, $9.5 \mathrm{~mL}$ of $10 \mathrm{mM}$ reduced glutathione (GSH) in $100 \mathrm{mM}$ phosphate buffer ( $\mathrm{pH}$ 6.5) were mixed. Ten microliters of each insect homogenate was mixed with $200 \mu \mathrm{L}$ of freshly prepared GSH/CDNB working solution in a microtiter plate well. The enzyme reaction rate was measured at $340 \mathrm{~nm}$ at $12 \mathrm{~s}$ intervals for $5 \mathrm{~min}$. An extinction coefficient of $5.76 \mathrm{mM}^{-1}$ (corrected for the path length of $0.6 \mathrm{~cm}$ ) was used to convert the absorbance values to moles product. Thus, the GST activity per individual was reported as CDNB conjugated $\mu \mathrm{mol}$ product $\mathrm{min}^{-1} \mathrm{mg}^{-1}$ protein (Karunaratne \& Hemingway, 1996).

\section{Carboxylesterase assay}

A stock solution of $100 \mathrm{mM}$-nitrophenyl acetate ( $p$ NPA) was prepared in acetone. The working solution of $p$ NPA ( $1 \mathrm{mM}$ ) was prepared freshly for each assay by adding $50 \mu \mathrm{L}$ of $100 \mathrm{mM} p$ NPA stock solution into $5 \mathrm{~mL}$ of $50 \mathrm{mM}$ phosphate buffer ( $\mathrm{pH} 7.4$ ). Ten microliters of each homogenate were mixed with $200 \mu \mathrm{L}$ of the $1 \mathrm{mM}$ $p$ NPA working solution in a microliter plate well. The reaction rate was read immediately at $12 \mathrm{~s}$ intervals at $405 \mathrm{~nm}$ for $2 \mathrm{~min}$ at $21{ }^{\circ} \mathrm{C}$. An extinction coefficient of $6.53 \mathrm{mM}^{-1}$ (correlated for the path length of $0.6 \mathrm{~cm}$ ) was used to convert the absorbance values to moles product. The $p$ NPA activity per individual was reported as $\mu \mathrm{mol}$ product $\mathrm{min}^{-1} \mathrm{mg}^{-1}$ protein.

\section{Cytochrome P450 monooxygenase assay}

Twenty microliters of each insect homogenate were mixed with $80 \mu \mathrm{L}$ of potassium phosphate buffer $(\mathrm{pH}$ 7.2) $+200 \mu \mathrm{L}$ of $6.3 \mathrm{mM}$ tetramethylbenzidine (TMBZ) working solution $[0.01 \mathrm{~g}$ TMBZ dissolved in $5 \mathrm{~mL}$ methanol and then in $15 \mathrm{~mL}$ of sodium acetate buffer $(\mathrm{pH} 5.0)+25 \mathrm{PI}$ of $3 \% \mathrm{H}_{2} \mathrm{O}_{2}$ solution] in a microtiter plate well. After $2 \mathrm{~h}$ of incubation at room temperature, the plate was read at $630 \mathrm{~nm}$ as an endpoint assay. This assay does not measure the monooxygenase activity but titrates the amount of heme in the mosquito homogenate. Since heme is present in the active site of the monooxygenases, the amount of heme corresponds to the amount of monooxygenases present. Using a standard curve of cytochrome $\mathrm{C}$, an estimate of the amount of monooxygenases present was obtained and expressed as equivalent units of cytochrome P450.

\section{Protein assay}

To obtain specific activities of enzymes, protein concentrations of the tick homogenates were determined by BIO-RAD protein determination kit, using bovine serum albumin as the standard protein. Ten microliters of homogenate were mixed with $300 \mu \mathrm{L}$ of BIO-RAD working solution (prepared according to the instructions of the manufacturer), and the absorbance was read at 630 as an endpoint assay after a 5-minute incubation at room temperature.

\section{RESULTS AND DISCUSSION}

Dose-response mortalities against DDT, malathion, flumethrin and permethrin are summarized in Table 1 and the $\log$ concentration-probit mortalities are shown in Figures 1-4. No larval mortalities were detected in untreated controls. $\mathrm{LC}_{50}$ and $\mathrm{LC}_{90}$ (24 hours exposure) values along with 95\% confident intervals (CI) are listed in Table 2. Ninety-five percent CI values were narrow at $\mathrm{LC}_{50}$ and $\mathrm{LC}_{90}$ levels in all graphs except for malathion and DDT at the $\mathrm{LC}_{90}$ level, where they were much wider. Except for permethrin, $\chi^{2}$ values for the

Table 1: Percentage mortalities of Otobius megnini for malathion, flumethrin, permethrin and DDT as determined by Larval Packet Test (LPT) bioassays (FAO, 2004)

\begin{tabular}{ccccc}
\hline $\begin{array}{c}\text { Acaricide } \\
\text { concentration } \\
(\%)\end{array}$ & Malathion & Flumethrin & Permethrin & DDT \\
\hline 0.00001 & $*$ & 7.29 & $*$ & $*$ \\
0.0001 & 12.28 & 7.89 & 7.65 & 1.77 \\
0.0005 & 27.91 & $*$ & 16.22 & $*$ \\
0.00075 & $*$ & $*$ & 17.53 & $*$ \\
0.001 & 18.31 & 81.50 & 22.81 & 3.56 \\
0.005 & 22.68 & $*$ & 47.92 & $*$ \\
0.01 & 62.92 & 98.74 & 53.43 & 4.70 \\
0.05 & $*$ & 99.62 & $*$ & $*$ \\
0.1 & 63.86 & 99.62 & 100 & 11.30 \\
0.5 & 50.00 & 100 & $*$ & $*$ \\
1 & 97.78 & $*$ & $*$ & 59.77 \\
2 & $*$ & $*$ & $*$ & 93.97 \\
5 & $*$ & $*$ & $*$ & 99.46 \\
7 & $*$ & $*$ & $*$ & 100 \\
\hline Not tested & & & &
\end{tabular}

\footnotetext{
* Not tested
} 
goodness-of-fit estimations were high and significant (Table 2). The regression coefficient was highest for permethrin and similar for the other three acaricides (Table 2). Since discriminating dosages of acaricides are not available for $O$. megnini in the literature, the resistance of $O$. megnini was measured using the established discriminating dosages for the Australian and Yeerongpilly strains of Rhipicephalus microplus (FAO, 2004) and anopheline mosquitoes (WHO, 2016). Although a direct determination of resistance cannot be made using discriminating dosages specified for other species, a comparison was attempted in order to obtain a rough estimation (Figures 1 to 4 and Table 2). According to anopheline discriminating dosages, the $O$. megnini population had possible resistant genes for malathion (2.93\% survivals), permethrin (5.38\%) and DDT (8.0\%). With Australian R. microplus discriminating dosages, $O$. megnini population was susceptible to flumethrin
$(0.05 \%$ survivals) but resistant to DDT $(13.77 \%$ survivals). However, O. megnini population was resistant to flumethrin when the discriminating dosage of the Ceremonially strain of $R$. microplus was considered (10.79\% survivals) (Table 2). It is important to develop separate discriminating dosages for $O$. megnini using a laboratory-maintained susceptible strain to obtain accurate results. S-shaped mortality curve in Figure 5 indicates the heterogenic response (i.e. both susceptible and resistant) of the O. megnini population to DDT (FAO, 2004). The mean specific activity levels of esterases and GSTs, and the amount of monooxygenases obtained from the biochemical assays were $0.064 \pm 0.008 \mu \mathrm{mol} \mathrm{min}^{-1}$ $\mathrm{mg}^{-1}, 0.104 \pm 0.05 \mu \mathrm{mol} \mathrm{min}{ }^{-1} \mathrm{mg}^{-1}$ and $0.068 \pm 0.02$ equivalent units of cytochrome P450, respectively. The percentage remaining activity of the target site AChE, after propoxur inhibition was $33.88 \pm 13.6$.

Table 2: $\quad \mathrm{LC}_{50}$ and $\mathrm{LC}_{90}$ values for malathion, flumethrin, permethrin, and DDT as determined by Larval Packet Test (LPT) acaricide bioassays (FAO, 2004) for the Sri Lankan population of Otobius megnini

\begin{tabular}{|c|c|c|c|c|c|c|c|c|c|}
\hline Acaricide & Slope & SE & $\begin{array}{l}\mathrm{LC}_{50}(\%) \\
(95 \% \mathrm{CI})\end{array}$ & $\begin{array}{l}\mathrm{LC}_{90}(\%) \\
(95 \% \mathrm{CI})\end{array}$ & $\chi^{2}(\mathrm{df})$ & $\mathrm{R}^{2}$ & DD (\%) & $\mathrm{R}(\%)$ & Resistance status $^{* *}$ \\
\hline $\begin{array}{l}\text { Malathion } \\
(\mathrm{n}=1741)\end{array}$ & 8.87 & 13.30 & $\begin{array}{c}0.011 \\
(0.048-0.002)\end{array}$ & $\begin{array}{c}0.722 \\
(60.284-0.113)\end{array}$ & $28.11^{*}(7)$ & 0.84 & $5^{\mathrm{a}}$ & 2.93 & Possible resistant \\
\hline \multirow[t]{2}{*}{$\begin{array}{l}\text { Flumethrin } \\
(\mathrm{n}=2567)\end{array}$} & 7.56 & 10.14 & $\begin{array}{c}0.0003 \\
(0.001-0.0001)\end{array}$ & $\begin{array}{c}0.004 \\
(0.015-0.001)\end{array}$ & $18.19^{*}(5)$ & 0.73 & $0.01^{\mathrm{bl}}$ & 0.05 & Susceptible \\
\hline & & & & & & & $0.0036^{\mathrm{b} 2}$ & 10.79 & Resistant \\
\hline $\begin{array}{l}\text { Permethrin } \\
(\mathrm{n}=2087)\end{array}$ & 10.88 & 2.60 & $\begin{array}{c}0.008 \\
(0.0132-0.0049)\end{array}$ & $\begin{array}{c}0.300 \\
(1.2112-0.111)\end{array}$ & $1.18(5)$ & 0.95 & $0.75^{\mathrm{a}}$ & 5.38 & Possible resistant \\
\hline \multirow[t]{2}{*}{$\begin{array}{l}\text { DDT } \\
(n=2013)\end{array}$} & 9.42 & 19.40 & $\begin{array}{c}0.124 \\
(2.852-0.013)\end{array}$ & $\begin{array}{c}3.049 \\
(1703.73-0.291)\end{array}$ & $51.53^{*}(6)$ & 0.77 & $4^{a}$ & 8.00 & Possible resistant \\
\hline & & & & & & & $2^{\mathrm{bl}}$ & 13.77 & Resistant \\
\hline
\end{tabular}

$\mathrm{N}=$ total number of individuals used; $\mathrm{SE}=$ standard error; $\mathrm{LC}=$ lethal concentration; $\mathrm{CI}=$ confident intervals; $\chi 2=$ goodness of fit $($ Log concentrationprobit transformed data); $\mathrm{R}^{2}=$ regression coefficient; $\mathrm{DD}=$ discriminating dosage; $\mathrm{R}=$ resistance percentage; ${ }^{*}=\mathrm{p}<0.05$

$\mathrm{a}=$ discriminating dosage for anopheline mosquitos (WHO, 2016)

$\mathrm{b}=$ discriminating dosage for ${ }^{\mathrm{b} 1}$ Australian and ${ }^{\mathrm{b} 2}$ Yeerongpilly strains of Rhipicephalus microplus (FAO, 2004).

** Resistance status was determined as susceptible (98-100 \% mortality), possible resistant (90-97.9\% mortality) and resistant (<90 \% mortality) (WHO, 2016)

This study reports the first evidence of the development of acaricide resistance in spinose ear ticks, which infest the horses in the world. Resistance status was assessed using the larval packet test described by Stone and Haydock (1962) and later adopted and recommended by the Food and Agriculture Organization (FAO, 2004). This is a low cost straightforward method, which has been widely used to assess the resistance levels in hard and soft ticks, including $R$. microplus, $R$. sanguineus,
Hyalomma anatolicum and Ornithodoros savignyi (Miller et al., 2001; Ahmed et al., 2007; Lovis et al., 2011; Shyma et al., 2012; Bandara \& Karunaratne, 2017). Ahmed et al. (2007) executed the same larval packet test for the soft tick $O$. savignyi but did not provide a discriminative dosage. Recently, Surbhi et al. (2018) used an adult immersion test for resistance trials in $O$. savignyi but results from this technique were difficult to compare with LPT results. 


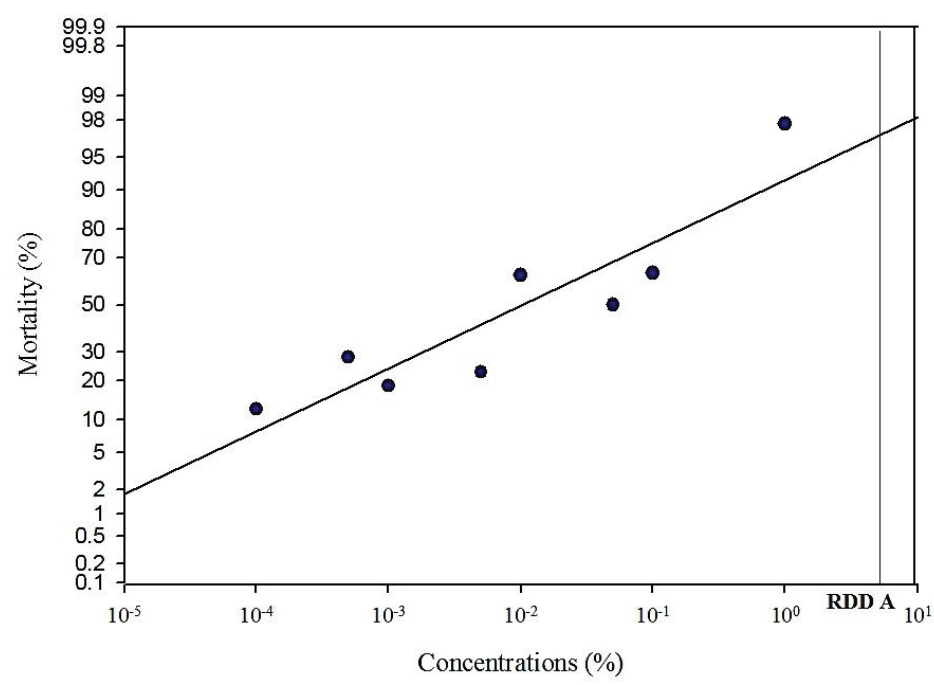

Figure 1: Log concentration-probit mortality of Otobius megnini for malathion as determined by the Larval Packet Test (LPT). The RDD A line indicates the resistance discriminating dosage (5\%) for anopheline mosquitos (WHO, 2016).

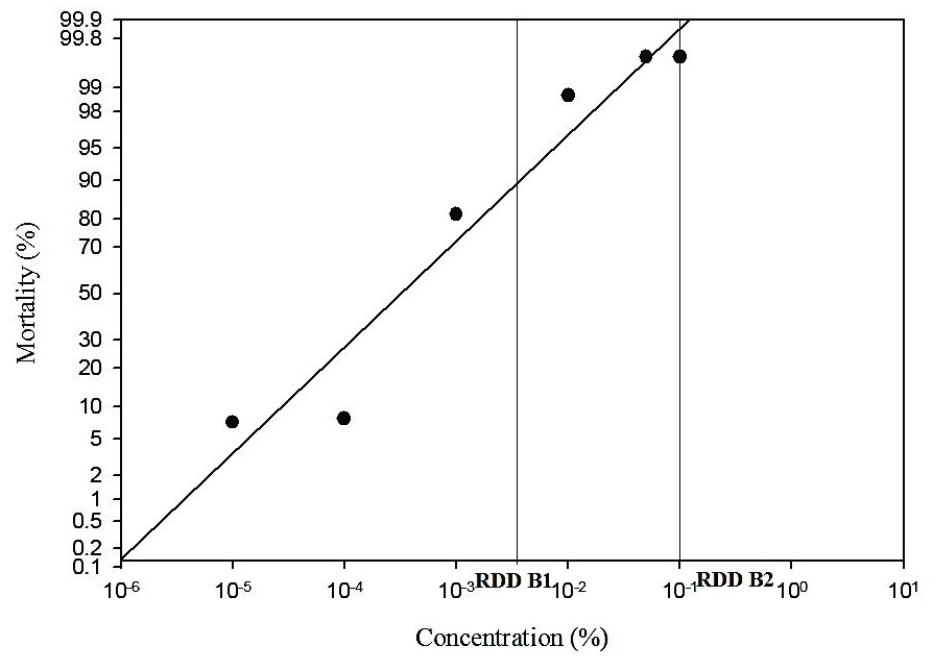

Figure 2: Log concentration-probit mortality of Otobius megnini for flumethrin as determined by the Larval Packet Test (LPT). The RDD B1 and RDD B2 lines indicate the resistance discriminating doseages for Australian $(0.0036 \%)$ and Yeerongpilly strains $(0.01 \%)$ of Rhipicephalus microplus, respectively (FAO, 2004).

The discriminative dosage is generally assessed by doubling the mean $\mathrm{LC}_{99.9}$ for a particular acaricide derived from a susceptible population (WHO, 2016). Susceptible strains of ticks are usually maintained under optimal conditions within laboratories for generations. Since this is the first study carried out in Sri Lanka for O. megnini, a reliable susceptible-haplotype could not be found during the investigation. Since data for a susceptible $O$. megnini population were lacking, discriminating dosages available for hard tick R. microplus (FAO, 2004) were 
used to assess the acaricide susceptibility of $O$. megnini. The presence of resistance was seen only against DDT. Two Sri Lankan populations of $R$. microplus have shown $\mathrm{LC}_{50}$ values of $0.04 \%$ and $0.03 \%$ for malathion, $0.002 \%$ and $0.001 \%$ for permethrin, $3.68 \%$ and $0.21 \%$ for DDT, respectively (Bandara \& Karunaratne, 2017). In comparison to Bandara and Karunaratne (2017), the present study showed that the tested $O$. megnini population has a similar $\mathrm{LC}_{50}$ value for malathion, a higher value for permethrin and a lower value for DDT.

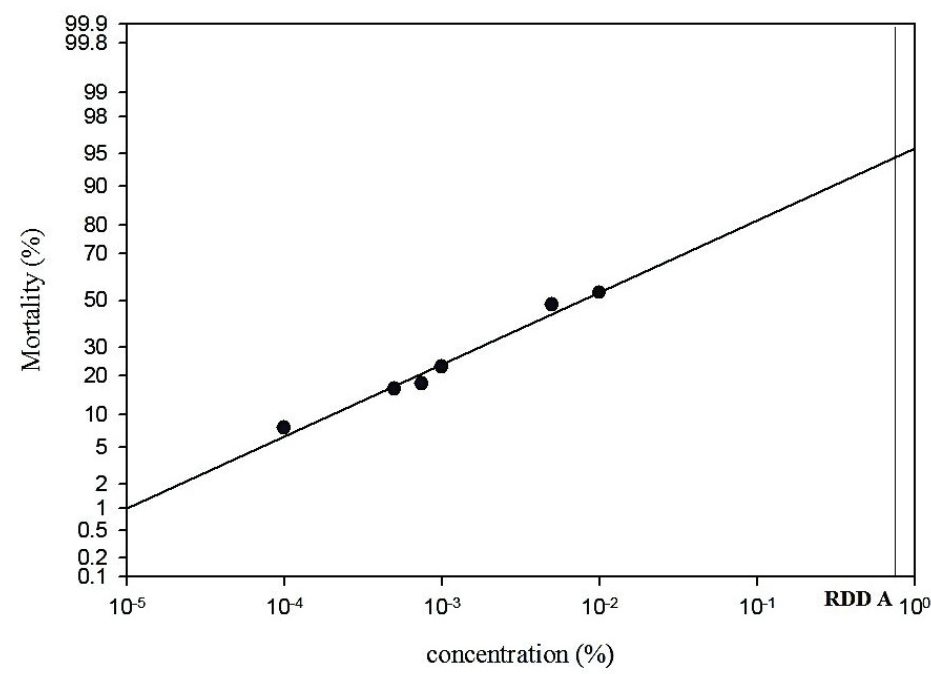

Figure 3: Log concentration-probit mortality of Otobius megnini for permethrin as determined by the Larval Packet Test (LPT). The RDD A line indicates the resistance discriminating dosage $(0.75 \%)$ for anopheline mosquitos (WHO, 2016).

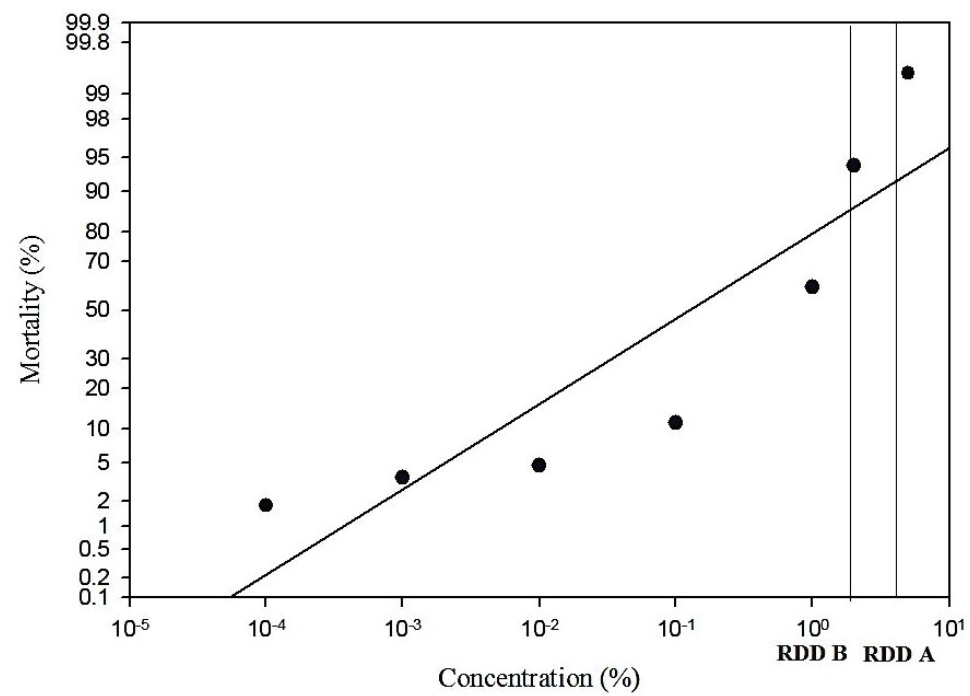

Figure 4: Log concentration-probit mortality of Otobius megnini for DDT as determined by the Larval Packet Test (LPT). The RDD A and RDDB lines indicate the resistant discriminating dosages for anopheline mosquitos (4\%) and Rhipicephalus microplus (2\%), respectively (FAO, 2004; WHO, 2016). 
However, mortality outcomes must be analysed carefully and interpreted cautiously when comparing data across different species as there are several species-specific interfering factors, including rate of acaricide/ insecticide absorption and physiology of the organism, which can contribute to the mortality rate.

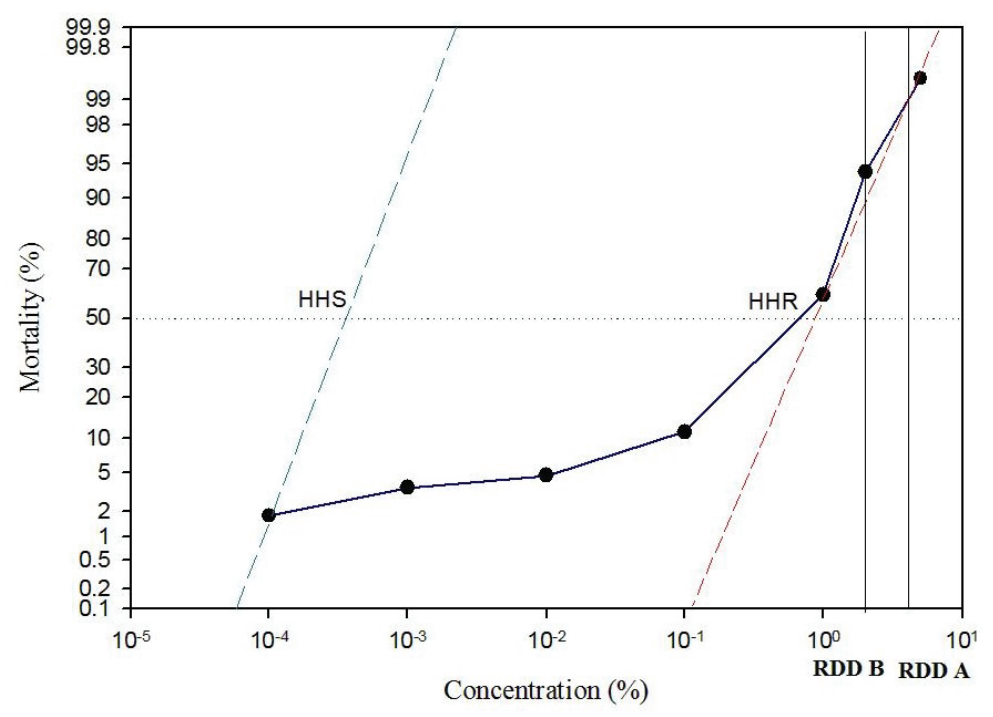

Figure 5: Line and scatter plot for the mortality response of $O$. megnini to DDT as determined by the Larval Packet Test (LPT). The RDD A and RDDB lines indicate the resistant discriminating dosages for anopheline mosquitos (4\%) (WHO, 2013) and $R$. microplus (2\%) (FAO, 2004), respectively. The two parallel broken lines represent hypothetical homogeneously susceptible (HHS) and hypothetical homogeneously resistant (HHR) populations.

Log concentration-probit mortality of DDT for the $O$. megnini population did not fit into a linear regression line indicating heterogeneous response for DDT (WHO, 2016; Karunaratne et al., 2018). The high slope in the regression line with low $\mathrm{LC}_{50}$ and $\mathrm{LC}_{90}$ values indicated that the population was homozygous susceptible for flumethrin. However, there are no previous studies for O. megnini for comparison.

In Sri Lanka, DDT was extensively used in agriculture and to control malaria vectors for more than three decades (Kondradsen et al., 2000) until it was replaced by malathion in the mid-1970s due to the development of resistance in Anopheles mosquitos (Kondradsen et al., 2000). The use of organophosphates was legally limited to the health sector and carbamate was limited to the agricultural sector as a strategy to prevent resistance development. In the $1990 \mathrm{~s}$, pyrethroids were introduced to both agriculture and health sectors to control insect pests/ vectors. Presently, pyrethroids are widely utilized in tick control programs in the country (personal communication with veterinarians). The results of our study showed the presence of resistance for DDT of $O$. megnini despite the absence of DDT usage for more than four decades. It has been reported that intensive use of DDT in antimalarial and agricultural programs within the country from 1946 to 1977 has caused irreversible DDT resistance in almost all arthropod species including mosquitoes, bedbugs, ticks and agricultural pests (Damayanthi \& Karunaratne, 2005; Karunaratne et al., 2007, 2013; Perera et al., 2008; Bandara \& Karunaratne, 2017). This may be due to the selection of the same molecular mechanism initially developed to provide DDT resistance to O. megnini using insecticides. Alternatively, the evolved resistance mechanisms for other molecules may also be capable of causing DDT resistance in O. megnini (Bandara \& Karunaratne, 2017).

Metabolic resistance based on GSTs is the major mechanism of DDT resistance (Hemingway et al., 2004; Karunaratne et al., 2018). Susceptible populations of the mosquitoes Anopheles gambiae and Culex 
quinquefasciatus had GST specific activities of $0.42 \pm$

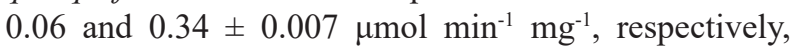
which was higher than the observed specific activity of $O$. megnini $\left(0.104 \pm 0.007 \mu \mathrm{mol} \mathrm{min}{ }^{-1} \mathrm{mg}^{-1}\right)$ tested in the present study. Bandara and Karunaratne (2017) reported 0.38 and $0.13 \mu \mathrm{mol} \mathrm{min}{ }^{-1} \mathrm{mg}^{-1}$ for Sri Lankan $R$. microplus. Therefore, it appears that GSTs are not responsible for the observed high DDT tolerance of $O$. megnini. The presence of mutations in the DDT target site, which is the voltage-gated sodium channel (VGSC) on the nerve membranes, may provide this resistance by making the target site insensitive to DDT. Although the pyrethroids share this target site, mutations of VGSC gene which provide DDT resistance does not necessarily provide resistance to pyrethroids (Hemingway et al., 2004).

Increased esterase activity is a well-known mechanism for protecting organophosphates and carbamates as they are rich with ester bonds (Karunaratne et al., 2018). The $O$. megnini population showed an esterase activity of $0.06 \pm 0.01 \mu \mathrm{mol} \mathrm{min}^{-1} \mathrm{mg}^{-1}$, which is higher than that of a susceptible population $\left(0.02 \pm 0.007 \mu \mathrm{mol} \mathrm{min}^{-1} \mathrm{mg}^{-1}\right)$ but lower than that of a resistant population $(0.92 \pm 0.08$

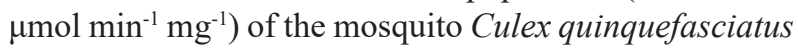
(Karunaratne \& Hemingway, 1996). Two R. microplus tick populations with esterase-based resistance had 0.09 \pm 0.02 and $0.08 \pm 0.04 \mu \mathrm{mol} \mathrm{min}^{-1} \mathrm{mg}^{-1}$ esterase activities (Bandara \& Karunaratne, 2017). Esterases of O. megnini population may therefore play a role in the development of resistance against organophosphates similar to the malathion. The results of AChE assay can be used to distinguish susceptible homozygous $(<30 \%$ remaining activity), heterozygous (30-70\% remaining activity), and resistant homozygous ( $>70 \%$ remaining activity) populations for altered or insensitive $\mathrm{AChE}$ mechanisms (WHO, 1998b). Accordingly, the O. megnini population has slightly more than $30 \%$ remaining activity indicating that the resistant alleles have been introduced in the population, expressing altered $\mathrm{AChE}$ mechanism, which in turn act in OP resistance.

Monooxygenases are an essential and diverse family of heme-containing enzymes which unitize as a resistance mechanism against pyrethroids (Karunaratne et al., 2018). A discriminating amount of 0.35 equivalent units of cytochrome P450 was introduced to enhance monooxygenase activity. The introduced amount of cytochrome P450 was based on the monooxygenase amounts given for susceptible An. culicifacies and An. subpictus by Perera et al. (2008). The Sri Lankan cattle tick $R$. microplus had 0.14 and 0.34 equivalent units of cytochrome P450 as monooxygenase amounts from two populations (Bandara \& Karunaratne, 2017). Since the studied $O$. megnini population had a lower amount of monooxygenase activity $(0.068 \pm 0.02$ equivalent units of cytochrome P450), it can be inferred that this mechanism is absent in O. megnini population and does not support pyrethroid resistance.

The incidence of acaricide resistance is highest in one-host ticks with short life cycles such as R. microplus compared to multi-host ticks (Wharton \& Roulston 1970; Shyma et al., 2013). This is because one-host ticks spend a more significant period of their life cycle on the same host under constant exposure to chemical acaricide/insecticides (Kiffner et al., 2011; Leger et al., 2013). Although most soft ticks have multi-host feeding patterns with shorter parasitic periods, O. megnini has a one-host life cycle with a high degree of host and feeding site predilection (Sonenshine, 1993).

\section{CONCLUSION}

Otobius megnini collected from racehorses from Nuwara Eliya, Sri Lanka, are susceptible to flumethrin and resistant to DDT. The development of organophosphate resistance through enhanced activity of esterases and altered target site $\mathrm{AChE}$ were evident. Future research is needed to generate more information on the persistence of acaricide resistance in $O$. megnini.

\section{Conflict of interest}

The authors declare that they have no competing interests

\section{Acknowledgements}

Authors thank USDA-ARS Knipling-Bushland U.S. Livestock Insects Research Laboratory, Kerrville, TX 78028 , USA for the instructions on preparing acaricide impregnated papers, and the management of the racecourse in Nuwara Eliya, T.D.B. Lenadora, W.M.N. Wanninayake and Shantha Bandara for their support in tick collection. Laboratory assistance from Nalaka Nugapola and financial assistance from the National Research Council, Sri Lanka (grant11-44) are gratefully acknowledged.

\section{REFERENCES}

Ahmed M.I., Shinggu P.A. \& Basu A.K. (2007). Susceptibility of the soft tick Ornithodoros savignyi to different classes of acaricides. Nigerian Journal of Parasitology 24(1): 
179-184.

DOI: https://doi.org/10.4314/njpar.v24i1.37824

Bandara K.J. \& Karunaratne S.H.P.P. (2017). Mechanisms of acaricide resistance in the cattle tick Rhipicephalus (Boophilus) microplus in Sri Lanka. Pesticide Biochemistry and Physiology 139: 68-72.

DOI: https://doi.org/10.1016/j.pestbp.2017.05.002

Damayanthi B.T. \& Karunaratne S.H.P.P. (2005). Biochemical characterization of insecticide resistance in insect pests of vegetables and predatory ladybird beetles. Journal of the National Science Foundation of Sri Lanka 33(2): 115-122: DOI: https://doi.org/10.4038/jnsfsr.v33i2.2341

Desjardins I. et al. (11 authors) (2018). Seroprevalence of horses to Coxiella burnetii in an $\mathrm{Q}$ fever endemic area. Veterinary Microbiology 215: 49-56.

DOI: https://doi.org/10.1016/j.vetmic.2017.11.012

Diyes G.C.P. \& Rajakaruna R.S. (2017). Life cycle of Spinose ear tick, Otobius megnini (Acari: Argasidae) infesting the race horses in Nuwara Eliya, Sri Lanka. Acta Tropica 166: $164-176$.

DOI: https://doi.org/10.1016/j.actatropica.2016.11.026

Diyes G.C.P., Rajapaksha R.P.V.J. \& Rajakaruna R.S. (2018). Molecular evidence of Babesia infections in spinose ear tick, Otobius megnini infesting stabled horses in Nuwara Eliya racecourse. Ceylon Journal of Science 47(4): 405-409.

DOI: https://doi.org/10.4038/cjs.v47i4.7559

Estrada-Peña A. \& Jongejan F. (1999). Ticks feeding on humans: a review of records on human-biting Ixodoidea with special reference to pathogen transmission. Experimental and Applied Acarology 23: 685-715.

DOI: https://doi.org/10.1023/a:1006241108739

FAO (2004). Guidelines for Resistance Management and Integrated Parasite Control in Ruminants. Module 1Ticks: Acaricide resistance: Diagnosis, Management and prevention, pp. 4-55. Animal Product and Health Division, Food and Agriculture Organization, Rome, Italy.

Fivaz B.H., Botha P. \& Cairns L.M. (1991). A putative outbreak of equine Lyme borreliosis in Natal. Journal of the South African Veterinary Association 61: 128-129.

Graf J.F., Gogolewski R., Leach-Bing N., Sabatini G.A., Molento M.B., Bordin E.L. \& Arantes G.J. (2004). Tick control: an industry point of view. Parasitology 129: s427-s442.

DOI: https://doi.org/10.1017/s0031182004006079

Hemingway J., Hawkes N.J., McCarroll L. \& Ranson H. (2004). The molecular basis of insecticide resistance in mosquitoes. Insect Biochemistry and Molecular Biology 34(7): 653-665.

DOI: https://doi.org/10.1016/j.ibmb.2004.03.018

Karunaratne S.H.P.P. \& Hemingway J. (1996). Different insecticides select multiple carboxylesterase isoenzymes and different resistance levels from a single population of Culex quinquefasciatus. Pesticide Biochemistry and Physiology 54: 4-11.

DOI: https://doi.org/10.1006/pest.1996.0003

Karunaratne S.H.P.P., Damayanthi B.T., Fareena M.H.J., Imbuldeniya V. \& Hemingway J. (2007). Insecticide resistance in the tropical bedbug Cimex hemipterus. Pesticide Biochemistry and Physiology 88: 102-107.

DOI: https://doi.org/10.1016/j.pestbp.2006.09.006

Karunaratne S.H.P.P., Weeraratne T.C., Perera M.D.B. \& Surendran S.N. (2013). Insecticide resistance and, efficacy of space spraying and larviciding in the control of dengue vectors Aedes aegypti and Aedes albopictus in Sri Lanka. Pesticide Biochemistry and Physiology 107: 98-105. DOI: https://doi.org/10.1016/j.pestbp.2013.05.011

Karunaratne S.H.P.P., De Silva W.A.P.P., Weeraratne T.C. \& Surendran S.N. (2018). Insecticide resistance in mosquitoes: Development, mechanisms and monitoring. Ceylon Journal of Science 47(4): 299-309.

DOI: https://doi.org/10.4038/cjs.v47i4.7547

Kiffner C., Vor T., Hagedorn P., Niedrig M. \& Ruhe F. (2011). Factors affecting patterns of tick parasitism on forest rodents in tick-borne encephalitis risk areas, Germany. Journal of Parasitology Research 108: 323-335. DOI: https://doi.org/10.1007/s00436-010-2065-x

Konradsen F., Amerasinghe F.P., van der Hoek W. \& Amerasinghe P.H. (2000). Malaria in Sri Lanka: Current Knowledge on Transmission and Control. International Water Management Institute.

Leger E., Vourch G., Vial L., Chevillon C. \& McCoy K.D. (2013). Changing distributions of ticks: causes and consequences. Experimental and Applied Acarology 59: 219-244.

DOI: https://doi.org/10.1007/s10493-012-9615-0

Lovis L., Perret J.L., Bouvier J., Fellay J.M., Kaminsky R., Betscharta B. \& Sager H. (2011). A new in vitro test to evaluate the resistance level against acaricides of the cattle tick, Rhipicephalus (Boophilus) microplus. Veterinary Parasitology 182: 269-280.

DOI: https://doi.org/10.1016/j.vetpar.2011.06.004

Madigan J.E., Valberg S.J., Ragle C. \& Moody J.L. (1995). Muscle spasms associated with ear tick (Otobius megnini) infestations in five horses. Journal of the American Veterinary Medical Association 207: 74-76.

Miller R.J., George J.E., Guerrero F., Carpenter L. \& Welch J.B. (2001). Characterization of acaricide resistance in Rhipicephalus sanguineus (Latreille) (Acari: Ixodidae) collected from the Corozal army veterinary quarantine center, Panama. Journal of Medical Entomology 38(2): 298-302.

DOI: https://doi.org/10.1603/0022-2585-38.2.298

Miller R.J., Davey R.J. \& George J.E. (1999). Characterization of pyrethroid resistance and susceptibility to coumaphos in Mexican Boophilus microplus (Acari: Ixodidae). Journal of Medical Entomology 36(5): 533-538.

DOI: https://doi.org/10.1093/jmedent/36.5.533

Nava S., Guglielmone A.A. \& Mangold A.J. (2009). An overview of systematics and evolution of ticks. Frontiers in Bioscience 14(8): 2857-2877.

DOI: https://doi.org/10.2741/3418

Perera M.D.B., Hemingway J. \& Karunaratne S.P. (2008). Multiple insecticide resistance mechanisms involving metabolic changes and insensitive target sites selected in anopheline vectors of malaria in Sri Lanka. Malaria 
Journal 7(1): 168.

DOI: https://doi.org/10.1186/1475-2875-7-168

Shyma K.P., Kumar S., Sangwan A.K., Sharma A.K., Nagar G.,

Ray D.D. \& Ghosh S. (2013). Acaricide resistance status of Rhipicephalus (Boophilus) microplus and Hyalomma anatolicum collected from Haryana. Indian Journal of Animal Sciences 83(6): 591-594.

DOI: https://doi.org/10.1007/s10493-016-0046-1

Shyma K.P., Kumar S., Sharma A.K., Ray D.D. \& Ghosh S. (2012). Acaricide resistance status in Indian isolates of Hyalomma anatolicum. Experimental and Applied Acarology 58(4): 471-481.

DOI: https://doi.org/10.1007/s10493-012-9592-3

Sonenshine D.E. (1993). Biology of Ticks. 2. Oxford University Press, New York, USA.

Stone B. F. \& Haydock. K.P. (1962). A method for measuring the acaricide-susceptibility of the cattle tick Boophilus microplus (Canestrini). Bulletin of Entomological Research 53: 563-578.
DOI: https://doi.org/10.1017/s000748530004832x

Surbhi Gupta S., Sangwan A.K. \& Sangwan N. (2018). Determination of efficacy of commercial acaricides against Ornithodoros savignyi ticks collected from Haryana. Journal of Entomology and Zoology Studies 6: $237-239$.

Wharton R.H. \& Roulston W.J. (1970). Resistance of ticks to chemicals. Annual Review of Entomology 5: 381-403. DOI: https://doi.org/10.1146/annurev.en.15.010170.002121

WHO (1998a). Test procedures for insecticide resistance monitoring in malaria vectors, bio efficacy and persistence of insecticides on treated surfaces. World Health Organization, Geneva, Switzerland.

WHO (1998b). Techniques to detect insecticide resistance mechanisms (field and laboratory manual). World Health Organization, Geneva, Switzerland.

WHO (2016). Test procedures for insecticide resistance monitoring in malaria vector mosquitoes. World Health Organization, Geneva, Switzerland. 